\title{
Effects of quinine sulfate- an antimalarial drug on palatal growth in developing mice embryo: A histopathological study
}

\author{
Soubhagya Ranjan Nayak', Latha V. Prabhu², C. V. Raghuveer ${ }^{3}$ \\ ${ }^{1}$ Associate Professor, Department of Anatomy, College of Medicine \& J.N.M. Hospital, WBUHS, Kalyani, Nadia, West \\ Bengal-741235, 2'Professor, Department of Anatomy, CBS, Bejai, Kasturba Medical College, Mangalore, Manipal \\ University, Karnataka-575004, ${ }^{3}$ Vice-Chancellor, Sri Devaraj Urs Academy of Higher Education and Research, Kolar, \\ Karnataka-563101, India
}

Background: Malaria is one of the most common infectious and fatal diseases worldwide. Quinine sulfate is one of the antimalarial drug used to treat chloroquine resistant malaria and malaria falciparum. Aims and Objectives: The present study was designed to assess its developmental defects on mice palate. Materials and Methods: Thirty adult pregnant female Swiss albino mice were used in the present work. They were divided into five groups of six each. One control group (c) with 6 pregnant mice received normal saline orally from day 6 to 15 of gestation. Four treated groups of 6 pregnant mice each were formed. Treated groups T1, T2, T3 and T4 were administered Quinine sulfateorally with 50, 100, $200,400 \mathrm{mg} / \mathrm{kg}$ bw/day from day 6 to 15 of gestation respectively. Results: No palatal abnormalities were observed histologically in the control and T1 treated group. However, varying degrees of clefting of the palate, from failure of elevation of the palatal shelves to failure of fusion in the midline were observed in the Quinine sulfate treated groups (T2, T3 \& T4). Conclusion: Quinine sulfate induced defects in the developing palate in the present study by disturbing the process of palatogenesis, which is characterized by incomplete growth, elevation or fusion of the palatal shelves.

Key words: Quinine; Teratologenesis; Clefting; Mesenchyma

\section{INTRODUCTION}

Many great discoveries have been made by chance but some have been the result of human perseverance and ingenuity. A sterling example is the discovery of quinine in Peru and is now produced in Java. Quinine has gone through centuries without losing its medical efficacy that efficacy allowed the exploration and colonization of Africa and played a key role in the ability to conduct overseas military campaigns. ${ }^{1}$ Quinine is the oldest drug used to treat malaria and it remains widely used. It is especially valuable in the treatment of severe or drug resistant P. falciparum infections. It is considered to be safe during pregnancy although the evidence is limited and it is known to cause hypoglycaemia. ${ }^{2}$ Quinine was first used in the $17^{\text {th }}$ century as a prophylactic against malaria.
Quinine remains the prototype blood schizontocide for the suppressive treatment and cure of chloroquineresistant and multidrug-resistant falciparum malaria. ${ }^{3} \mathrm{At}$ the beginning of the 1970s, researchers became interested in the antiviral properties of antimalarial drugs. Today, quinine is still used to treat chloroquine and multidrug resistant Plasmodium falciparum, as well as severe cerebral infestation. ${ }^{4-6}$ Recently quinine is used in the treatment of autoimmune disorders such as Lupus and rheumatoid arthritis. ${ }^{7}$ QS is also widely used to treat patients with autoimmune dermatologic and rheumatologic diseases, and additional therapy for patients with HIV infection. These patients, who are often immuno-compromised, may receive a secondary advantage from these antimalarials, which may provide some protection against staphylococci and E. agglomerans. ${ }^{8}$ The efficacy of the quinine will 
continue to play a significance role in the management of multidrug-resistant malaria.?

Although the efficacy of quinine is immense in the treatment of chloroquine-resistant and multidrug-resistant falciparum malaria, there are also a few reports on its teratogenic effects in pregnancy. However, there are not enough evidence to demonstrate the teratogenic and toxic effect of quinine sulfate (QS) on the craniofacial abnormalities in the humans and experimental animals. Present study was carried out to determine the effect of QS on the palatal growth of mice embryos; in control and various treated groups in detail.

\section{MATERIALS AND METHODS}

Chemical: Quinine sulfate was obtained from "LobaChemiePvt Ltd" (Mumbai, India). The chemical was of analytical grade.

Animals: A total of 30 sexually mature Swiss albino female mice (musdomesticusdomesticus), each of 8 to 10 weeks old weighing approximately 20-35 g were housed in the institutional animal house. The mice were housed in sanitized polypropylene cages containing sterile paddy husk as bedding. The animals were maintained under standard laboratory conditions of temperature $\left(23-28^{\circ} \mathrm{C}\right)$, humidity (30-70\%), and a 12-h light dark cycle. All animals were allowed free access to filter-purified tap water ad libitum and fed on a commercial diet (Hindustan Lever, Mumbai, India). All the studies conducted were approved by the Institutional Animal Ethical Committee (No. IAEC/KMC/06/2006_2007), Kasturba Medical College, Mangalore, according to prescribed guide-lines of the Committee for the Purpose of Control and Supervision of Experiments on Animals (CPCSEA), Government of India.

Female mice during their pro-estrous phase of estrous cycle were caged overnight with the males of the same stock (Female: Male=3:1). The vaginal smear was examined next morning at $8.00 \mathrm{a} . \mathrm{m}$. presence of spermatozoa in the smear was taken as day 'zero' of pregnancy. A total of 30 pregnant mice divided into 5 groups of 6 each were studied.

Acute Toxicity Studies: The five-day LD50 (Lethal Dose) for QS was found to be $800 \mathrm{mg} / \mathrm{kg}$ bw. The dose selected for assessment of teratogenic potential of QS was 1/2,1/4,1/8 and $1 / 16$ of the LD50 i.e. $400 \mathrm{mg} / \mathrm{kg}$ bw, $200 \mathrm{mg} / \mathrm{kg}$ bw, $100 \mathrm{mg} / \mathrm{kg}$ bw and $50 \mathrm{mg} / \mathrm{kg}$ bw respectively.

Experimental Groups: Thirty adult pregnant female Swiss albino mice (musdomesticusdomesticus) were used in the present work. They were divided into five groups of six each. One control group (c) with 6 pregnant mice received normal saline orally from day 6 to 15 of gestation. Four treated groups of 6 pregnant mice each were formed. Treated groups T1, T2, T3 and T4 were administered QS orally (oral gavage) with 50, 100, 200, $400 \mathrm{mg} / \mathrm{kg}$ bw/day from day 6 to 15 of gestation respectively (Table I). At the end of the experiment period; pregnant mice were sacrificed with overdose of ether anesthesia on day 18 of pregnancy (i.e. two days prior to full term). The uterine horns were exteriorized after opening the abdomen by midline incision. The sacs were inspected for sites of resorption and viable fetuses. The fetuses were removed from the uterus and were dried by wiping on a blotting paper, then weighted in Essae digital weighing balance. Bouin's solution was used for fixation $(96 \mathrm{hr}$, and then washed in $70 \%$ alcohol). ${ }^{10}$

Evaluation of Embryo Teratogenicity: The uterine horns were cut along the anti-mesometrial (greater) curvature and macroscopically examined. Finally each fetus was separated from its amniotic sac and placenta, which was individually weighed and grossly inspected. The fetuses were euthanized with intraperitoneal injection of pentobarbital. ${ }^{11}$ Following external observation, the heads of control and QS treated fetuses were fixed by immersion in Bouin's solution for more than $96 \mathrm{hr}$, and then transferred to $70 \%$ alcohol. Heads of selected control ( $n=2-3 /$ litter, chosen at random) and all the QS exposed fetuses were detached and cut transversely into 5 blocks using free hand cross section (Fig. 1) guided by external landmarks. ${ }^{12,13}$ For the detection of palatal abnormalities, the anterior region of the presumptive hard palate is chosen (Frontal planes 1\& 2; Fig 1). They were prepared for light microscopic study by paraffin sections, serially cut at 6 micro meters $(\mu \mathrm{m})$ in coronal plane. In each block of head every $7^{\text {th }}$ section was considered and stained with haematoxylin and eosin and mounted.

\section{RESULTS}

Palatal abnormalities: The percentage of palatal defects in the control and different treated groups were mentioned

\begin{tabular}{|c|c|c|}
\hline Groups & $\begin{array}{l}\text { Gestational days (GD) } \\
\text { of drug administration }\end{array}$ & Dose \\
\hline Control (C) & $6-15$ day of gestation & Normal saline \\
\hline Treated (T1) & $6-15$ day of gestation & $50 \mathrm{mg} / \mathrm{kg}$ bw/day \\
\hline Treated (T2) & $6-15$ day of gestation & $100 \mathrm{mg} / \mathrm{kg}$ bw/day \\
\hline Treated (T3) & $6-15$ day of gestation & $200 \mathrm{mg} / \mathrm{kg}$ bw/day \\
\hline Treated (T4) & $6-15$ day of gestation & $400 \mathrm{mg} / \mathrm{kg}$ bw/day \\
\hline
\end{tabular}


in the Table II. The palatal abnormalities are produced when elevation and subsequent fusion of the palatal shelves do not take place.

Control and $50 \mathrm{mg} / \mathrm{kg}$ bw (T1) groups: No abnormalitiesof thecontrol and T1 treated group heads were noted from the histological examination. Histologically the palatal shelves had fused (and with the nasal septum) and consequently the oral and nasal cavities were separated (Fig. 2A).

Palatal defects observed in the $100 \mathrm{mg} / \mathrm{kg}$ bw (T2), $200 \mathrm{mg} / \mathrm{kg}$ bw (T3) and $400 \mathrm{mg} / \mathrm{kg}$ bw (T4) treated groups: The palates exposed to QS were morphologically abnormal, and the fusion patterns were affected in the T2, T3 \& T4 groups. The severities of the morphological effects were dependent upon the concentration of QS. Control palatal shelves had elevated to the dorsum of the tongue and fused with the opposite side, separating the nasal cavity from the oral cavity. The palatal defects were more severe in the T4 treated group (37\%), followed by T3 and T4 treated groups, which had $10.5 \%$ and 5.5\% of palatal defects respectively. Palatogenesis is a complex developmental process that requires elevation and fusion

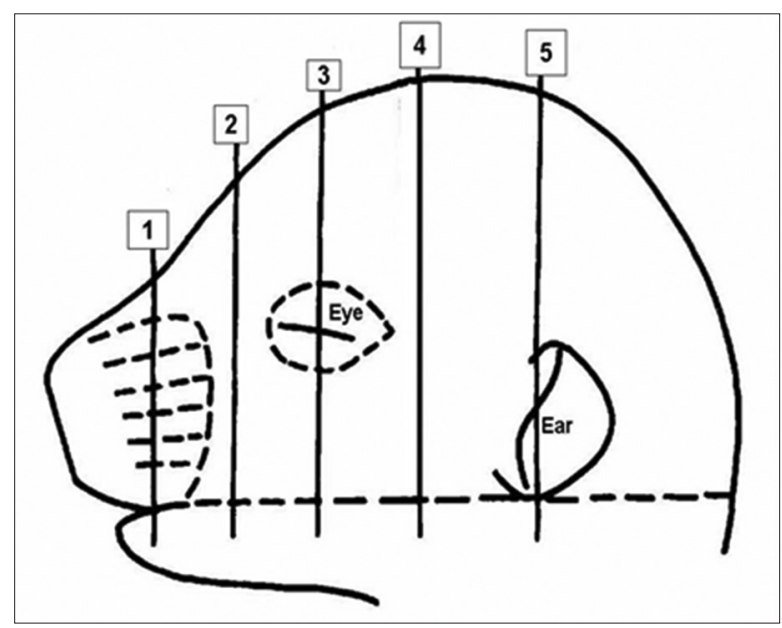

Figure 1: Profile of a fetal mouse head demonstrating external landmarks by which free hand transverse cross sections (frontal planes 1-5) were oriented to obtain reproducible sections for histopathological examination.For the detection of palatal abnormalities, the anterior region of the presumptive hard palate is chosen (frontal planes $1 \& 2$ ). of the palatal shelves. These processes are disrupted in the T2, T3 and T4 treated groups causing varying degrees ofclefting of the palate (Figs. 2 B, C, D), from failure of elevation of the palatal shelves (Figs. 3 A, B) to failure of fusion in the midline (Figs. 2 B, C).

\section{DISCUSSION}

Identification of environmental agents that cause damage to unborn children is absolutely necessary. Armed with the knowledge of those drugs, chemicals and foodstuffs that human beings are routinely exposed to that are truly teratogenic, exposures can be avoided, reduced or limited, and the incidence of tragic teratogen-induced birth defects drastically lowered.

Quinine has been used in the treatment of malaria and is still widely used worldwide. ${ }^{9}$ It is especially valuable in the treatment of severe or drug resistant Plasmodium falciparum infections. ${ }^{2}$ But its effect as a teratological agent is long debated and no conclusive evidence is available. Results of animal experiments so far reported are inconclusive too. To give additional information on the teratological effect of quinine, we performed present experiments using mice and specifically concentrated on its effect on palatal growth.

Cleft palate, with or without cleft lip, represents one of the most common birth defects observed in humans, occurring in approximately 1 in 700 live births. ${ }^{14,15}$ The mammalian palate develops from two primordia: the primary palate and the secondary palate. The primary palate represents only a small part of the adult hard palate. The secondary palate is primordium of the hard and soft parts of the palate. Palate develops in a multistep process that involves palatal shelf growth, elevation, midline fusion of palatal shelves, and the disappearance of midline epithelium seam. ${ }^{16}$ The palatal structures are composed of the central nervous system (CNS) derived ecto-mesenchyme and pharyngeal ectoderm. ${ }^{17,18}$ The epithelia that cover the palatal shelves are regionally divided into oral, nasal, and medial edge epithelium (MEE). ${ }^{16}$ The nasal and oral epithelia differentiate into pseudostratified and squamous epithelia,

\section{Table II: Palatal defects observed in the mice fetuses of the control and quinine sulfate treated groups.}

\begin{tabular}{|c|c|c|c|c|c|}
\hline \multirow[t]{2}{*}{ Groups } & Control (\%) & T1 (\%) & T2 (\%) & T3 (\%) & T4 (\%) \\
\hline & $n=58$ & $n=55$ & $n=54$ & $n=38$ & $n=27$ \\
\hline $\begin{array}{c}\text { Palatal defects } \\
\downarrow\end{array}$ & 0 & 0 & $3(5.5)$ & 4 (10.5) & $10(37)$ \\
\hline Unilateral & 0 & 0 & $1(1.8)$ & $2(5.2)$ & $4(14.8)$ \\
\hline Bilateral & 0 & 0 & $2(3.7)$ & $2(5.2)$ & $6(22.2)$ \\
\hline
\end{tabular}

$\mathrm{n}=$ number of variable fetuses 


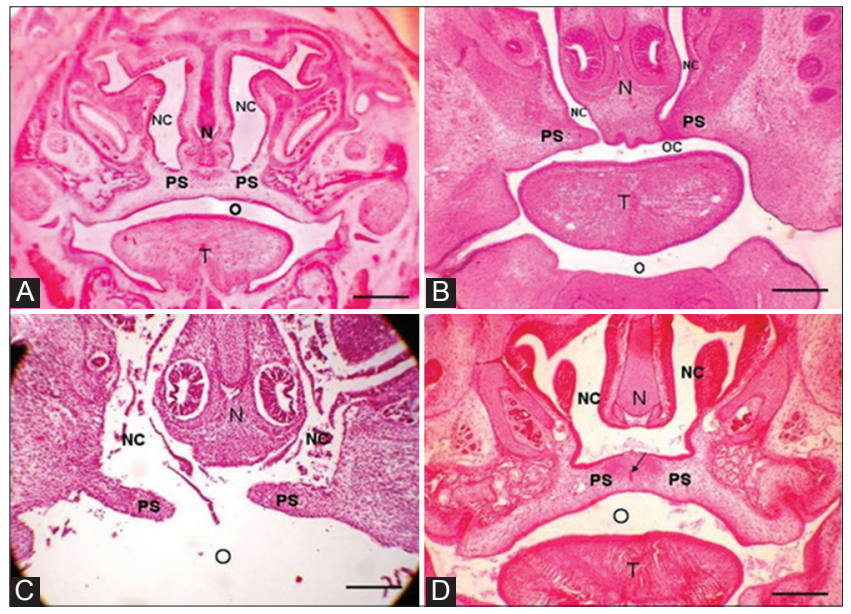

Figure 2: Palatal shelve growth comparison in the control and treated groups. A: Control; Coronal section of anterior region of the presumptive hard palate. Note the palatal shelves (PS) has been elevated and fused in the midline and with the nasal septum $(\mathrm{N})$, thus separating the nasal cavity $(\mathrm{NC})$ from the oral cavity $(\mathrm{O})$. ( $\mathrm{T}=$ tongue). $\mathrm{B}$ : $\mathrm{T} 3$; Coronal section of anterior region of the presumptive hard palate. Note that the left palatal shelve (PS) has fused with the nasal septum (N), but there is no fusion on the right, thus the nasal cavity (NC) and the oral cavity (O) communicating with each other forming unilateral cleft palate. ( $T=$ tongue). C: T4; Coronal section of anterior region of the presumptive hard palate. The two palatal shelves (PS) failed to meet and fuse with each other, leaving the gap between the nasal cavity $(\mathrm{NC})$ and oral cavity $(\mathrm{O})$ forming bilateral cleft palate. ( $\mathrm{T}=$ tongue). D: T4; Coronal section of a more posterior section through the presumptive hard palate. The nasal septum $(\mathrm{N})$ is unattached inferiorly leaving the gap between both the nasal cavities (NC). The palatal shelves are fused. Note the remaining of the midline epithelial seam (arrow). $(\mathrm{O}=$ oral cavity; T=tongue). Scale bar $200 \mu \mathrm{m}$.

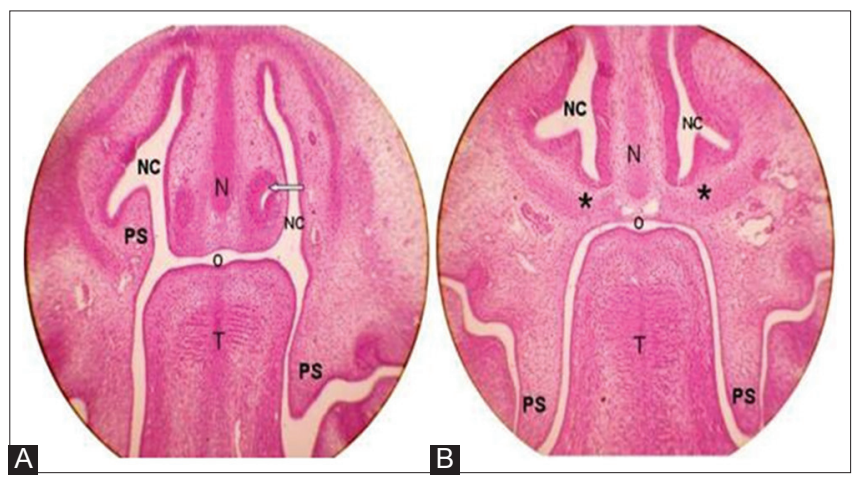

Figure 3:Faulty elevation of the palatal shelves: A: T4; Coronal section of the anterior region of the presumptive hard palate. The palatal shelves (PS) are in vertical position lateral to the tongue (T). The nasal septum $(\mathrm{N})$ is unattached inferiorly. The white arrow head indicates Jacobson's organ. ( $\mathrm{NC}=$ nasal cavity, $\mathrm{O}=$ oral cavity). $\mathrm{B}$ : T4; Coronal section of the posterior region of the presumptive hard palate. The palatal shelves (PS) are vertically oriented lateral to the tongue (T). The nasal septum $(\mathrm{N})$ has fused laterally with the lateral nasal walls (asterisks), separating the oral $(\mathrm{O})$ and nasal cavities (NC). Magnifications, $\times 4$

respectively; the MEE is removed from the fusion line by means of programmed cell death and cell migration. ${ }^{19,20}$

Palatal defects is one of the most serious congenital anomalies in humans that cause a sucking (breast feeding) problem in newborn babies and a morphologic deformity that usually leads to death in newborn mouse offspring due to an insufficient ability to suck milk. ${ }^{21}$ In humans, the frequency of palatal defects has been reported to increase in pregnant women affected with diabetes mellitus ${ }^{22}$ or epilepsy. ${ }^{23}$ The incidence of palatal defects are observed when methanol, ${ }^{2425}$ Triamcinolone acetonide, a synthetic glucocorticoid, ${ }^{26}$ 2,3,7,8-Tetrachlorodibenzop-dioxin (TCDD), a highly toxic halogenated aromatic hydrocarbon, ${ }^{27}$ corticosteroid ${ }^{28}$ and retinoic acid, ${ }^{29,30}$ administered in the pregnant rodents.

Anti-malarial drugs and drug combinations like sulfadoxine, pyrimethamine and sulfadoxine-pyrimethamine are known to have caused cleft palate in rodents. ${ }^{31-33}$ Mean time there are no such observations made in case of quinine., ${ }^{2,34}$ The administration of $\mathrm{H}$-triamcinolone acetonide on day 11.5 of the gestation caused a $100 \%$ frequency of cleft palate in $\mathrm{A} / \mathrm{J}$ mice. ${ }^{35}$ During morphogenesis of the lip and palate in the mouse fetus, the primary palate (including the upper lip and mucosa) arises from the fusion of the maxillary process, the nasal process, and the hard palate. At the onsets of secondary palate formation, the palatal processes lie vertically beside the tongue. A lowering of the mandible and the tongue allows for a rapid rotation of the palatal processes toward the horizontal position. The horizontally positioned palatal shelves begin to grow toward the midline where they meet and fuse to form a definitive palate. ${ }^{36} \mathrm{~A}$ change in the morphology of the posterior pharyngeal wall also assists in the horizontalization of the palatal shelves. Such a change occurred during palatogenesis, and the oropharyngeal tissues of the tongue and the pharynx might have thus contributed to the completion of palatogenesis. ${ }^{37}$

Palatal defects can be caused at different stages of palatogenesis as a result of incomplete growth, elevation or fusion of the palatal shelves, ${ }^{30,38}$ although the exact mechanism(s) remains unknown. For all the experiments reported in the present study QS treatment was commenced before the formation of palatal shelves, which in the mouse develop between embryonic day (E) 11.5 and 16.5. ${ }^{16}$ Treatment with QS was seen not to cause disruptions to the development of the nasal septum, but caused the failure of palatal shelf elevation, shelves to meet following elevation and the medial edge epithelial cell death; although the mechanism(s) by which this occurred are presently unclear, it is possible that the effect of QS treatment on the anterior region of the presumptive hard palate in these specimens might have prevented adequate enlargement of the palatal shelves to allow fusion to occur. The presence of the nasal septum allowed partial separation of the oral and nasal cavities by fusion of the nasal septum and the palatal shelves. More posteriorly, where the nasal septum undercuts and separates from the palatal shelves, the palatal 
shelves were close enough to allow fusion. The palatal shelves failed to reorient into a horizontal position only in the specimens treated QS. QS treatment may have caused modification in the extracellular matrix, or disruption of the mesenchymal cells, preventing the organisation of the palatal shelf mesenchyme necessary for elevation, ${ }^{39}$ in the present study.

QS induced defects in the developing palate in the present study by disturbing the process of palatogenesis, which is characterized by incomplete growth, elevation or fusion of the palatal shelves.

Limitation of the study: Small sample size and lack of inferential statistics.

\section{REFERENCES}

1. Seigneuric C, Camara B, Delmont J, Busato F, Payen JL, Armengaud M, et al.Quinquina and man. Med Trop 2008; 68:459-462.

2. Nosten F, McGready R, d'Alessandro $U$, Bonell A, Verhoeff $F$, Menendez $C$, et al. Antimalarial drugs in pregnancy: a review. Curr Drug Saf 2006; 1: 1-15.

3. Tracy JW and Webster LT. Drugs used in the chemotherapy of protozoal infections, Malaria, in Goodman and Gilman's The pharmacological basis of therapeutics, Joel G Hardman and Lee E. Limbird (ed-in-chief), Ninth edition, McGraw Hill, 1996.

4. Ibrahim MH, Elbashir MI, Naser A, Aelbasit IA, Kheir MM and Adam I. Low-dose quinine is effective in the treatment of chloroquine-resistant Plasmodium falciparum malaria in eastern Sudan. Ann Trop Med Parasitol 2004; 98:441-445.

5. Khan MA, Smego RA Jr, Razi ST and Beg MA. Emerging drug-resistance and guidelines for treatment of malaria. J Coll Physicians Surg Pak 2004; 14:319-324.

6. Alrajhi AA, Rahim I, Akood M and Hazmi M. Chloroquine-resistant plasmodium cerebral malaria in a chloroquine susceptible area. J Infect Dis 1999; 180:1738-1741.

7. Mates M, Nesher $G$ and Zevin S. Quinines--past and present. Harefuah 2007; 146:560-562.

8. Wolf R, Tufano MA, Ruocco V, Grimaldi E, Ruocco E, Donnarumma $G$, et al. Quinine sulfate inhibits invasion of some bacterial skin pathogens. Int J Dermatol 2006; 45:661-663.

9. Achan J, Talisuna AO, Erhart A, Yeka A, Tibenderana JK, Baliraine FN, et al. Quinine, an old anti-malarial drug in a modern world: role in the treatment of malaria. Malar J 2011; 10:144.

10. Bolon B, Welsch F and Morgan KT. Methanol induced neural tube defects in mice: Pathogenesis during neurulation. Teratology 1994; 49: 497-517.

11. Manson JM and Kang YJ. Test methods for assessing female reproductive and developmental toxicology. In: Hayes AW (ed.). Principles and methods of toxicology. $3^{\text {rd }}$ Ed, Raven Press, New York, 1994, pp. 989-1037.

12. Barrow MV and Taylor WJ. A rapid method for detecting malformations in rat fetuses. J Morphol 1969; 127: 291-306.

13. Kaufman $\mathrm{MH}$. The atlas of mouse development. Academic press, San Diego, 1992.

14. Gorlin RJ, Cohen MM and Hennekam RCM. Syndromes of the head and neck. Oxford, New York: Oxford University Press, 2001.

15. Murray JC. Gene/environment causes of cleft lip and/or palate.
ClinGenet 2002; 61:248-256.

16. Chai $Y$ and Maxson RE.Recent advances in craniofacial morphogenesis.DevDyn 2006; 235:2353-2375.

17. Ferguson MW. Palate development.Development 1988; 103 (Suppl):41-60.

18. Shuler CF. Programmed cell death and cell transformation in craniofacial development. Crit Rev Oral Biol Med 1995; 6:202-217.

19. Martínez-Alvarez C, Tudela C, Pérez-Miguelsanz J, O’Kane S, Puerta $\mathrm{J}$ and Ferguson MW.Medial edge epithelial cell fate during palatal fusion.DevBiol 2000; 220: 343-357.

20. Vaziri Sani F, Hallberg K, Harfe BD, McMahon AP, Linde A and Gritli-Linde A.Fate-mapping of the epithelial seam during palatal fusion rules out epithelial-mesenchymal transformation. DevBiol 2005; 285:490-495.

21. Nonaka K, Sasaki $\mathrm{Y}$, Watanabe $\mathrm{Y}$, Yanagita $\mathrm{K}$ and Nakata $\mathrm{M}$. Effects of fetus weight, dam strain, dam weight, and litter size on the craniofacial morphogenesis of CL/Fr mouse fetuses affected with cleft lip and palate. Cleft Palate Craniofac J 1997; 34:325-330.

22. Lowy C, Beard RW and Goldschmidt J. Congenital malformations in babies of diabetic mothers. Diabet Med 1986; 3:458-462.

23. Speidel BD and Meadow S. Maternal epilepsy and abnormalities of the fetus and newborn. Lancet 1972; 21:839-843.

24. Abbott BD, Logsdon TR and Wilke TS. Effects of methanol on embryonic mouse palate in serum-free organ culture.Teratology 1994; 49:122-134.

25. Bolon B, Dorman DC, Janszen D, Morgan KT and Welsch F. Phase-Specific Developmental Toxicity in Mice Following Maternal Methanol Inhalation. FundamApplToxicol 1993; 21:508-516.

26. Furukawa S, Usuda K, Abe M and Ogawa I. Histopathological findings of cleft palate in rat embryos induced by triamcinolone acetonide.J Vet Med Sci 2004; 66:397-402.

27. Yoon $\mathrm{BI}$, Inoue $\mathrm{T}$ and Kaneko $\mathrm{T}$. Teratological effect of 2,3,7,8-tetrachlorodibenzo-p-dioxin (TCDD): induction of cleft palate in the ddY and C57BL/6 mouse.J Vet Sci 2000; 1:113-119.

28. Silbermann M and Levitan S. Corticosteroid-induced mandibular growth retardation and palatal malformation in the ICR mouse fetus.J Anat 1979; 128:747-765.

29. Lotosh EA. Development of palate in normal murine embryo and the influence of various agents on the conditions of palatine plates at different stages of embryonic development. ActaChirPlast 1968; 10:1-6.

30. Abbott BD and Birnbaum LS. Retinoic acid-induced alterations in the expression of growth factors in embryonic mouse palatal shelves. Teratology 1990; 42:577-610.

31. Kato T and Kitagawa S. Production of congenital abnormalities in fetuses of rats and mice with various sulfonamides. Congenital Anomalies 1973; 13:7-13.

32. Shepard TH. Catalog of Teratogenic Agents. $8^{\text {th }}$ ed. Baltimore, MD: Johns Hopkins University Press, 1995.

33. Phillips-Howard PA and Wood D. The safety of antimalarial drugs in pregnancy. Drug Saf 1996; 14:131-145.

34. Lapointe $G$ and Nosal G. Saccharin- or quinine-induced changes in the rat pups following prolonged ingestion by the dam. Biol Neonate 1979; 36: 273-276.

35. Zimmerman EF and Bowen D. Distribution and metabolism of triamcinolone acetonide in mice sensitive to its teratogenic effects. Teratology 1972; 5:57-70.

36. Verrusio AC. A mechanism for closure of the secondary palate. Teratology 1970; 3:17-20. 
37. Clarke L, Hepworth WB, Carey JC and Seegmiller RE. Chondrodystrophic mice with coincidental agnathia: evidence for the tongue obstruction hypothesis in cleft palate. Teratology 1988; 38:565-570.

38. Ferguson MWJ. Developmental mechanisms in normal and abnormal palate formation with particular reference to the aetiology, pathogenesis and prevention of cleft palate. Brit J Orth $1981 ; 8: 115-137$

39. Moxham BJ. The development of the palate - a brief review. Eur J Anat 2003; 7 (Suppl 1):53-74.

\section{Authors Contribution:}

SRN- Concept and design of the study, data collection, manuscript preparation; LVP- Concept and design of the study and review of literature; CVR- Concept

and design of the study and critical revision of the manuscript.

Work Attributed to: Department of Anatomy, CBS, Bejai, KMC, Mangalore, Manipal University, Karnataka, India.

Orcid ID:

Dr. Soubhagya Ranjan Nayak - (D) https://orcid.org/0000-0002-3591-2363

Source of Support: Nil, Conflict of Interest: None declared. 